\title{
Düzlem İçi Eğilme Momenti Altındaki Elips Enkesitli T-birleşimlerinin Dayanımları
}

\author{
Resistance of Elliptical Hollow Section T-joints Under In-plane Bending Moment
}

\author{
Emre ÖZYURT*a ${ }^{\mathrm{a}}$, Murat YILMAZ ${ }^{\mathrm{b}}$ \\ Gümüşhane Üniversitesi, Mühendislik ve Doğa Bilimleri Fakültesi, İnşaat Mühendisliği Bölümü, 29100, Gümüşhane
}

\begin{tabular}{|c|c|c|}
\hline - Geliş tarihi / Received: 28.12 .2018 & - Düzeltilerek geliş tarihi / Received in revised form: 24.04.2019 & - Kabul tarihi / Accepted: 07.05.2019 \\
\hline
\end{tabular}

\begin{abstract}
Öz
Elips en kesitli içi boş profiller (EHS), son yıllarda estetik ve şık görünümlerinden ötürü popülerdir. Bu profiller mimarisel avantajlarının dışında, mühendislik açısından da bir çok avantajlara sahiptirler. Ancak, bu profillerden yapılmış birleşimlerin tasarımı için herhangi bir yönetmelik mevcut değildir. Yapılan tasarımlarda genellikle eşdeğer kutu profil yaklaşımı kullanılmaktadır. EHS'ler iki farklı çaplara sahip oldukları için, dört farklı oryantasyon ile birleşim türü oluşturulabilmektedir. Bu yüzden, eşdeğer kutu profil yaklaşımı her zaman ekonomik ve güvenli sonuçlar vermeyebilir. Bu çalışmanın amacı, mevcut yönetmelikteki eşdeğer kutu profil yaklaşımı kullanılarak EHS Tbirleşimlerinin düzlem içi eğilme momenti etkisindeki dayanımlarını ve göçme modlarını incelemektir. Bu çalışma, doğrusal olmayan sonlu elemanlar yazılımı olan ABAQUS v.6-14.1 programı kullanılarak gerçekleştirilmiştir. Sayısal analizlerden önce sonlu elemanlar modeli mevcut bir test ile karşılaş̧ırılarak doğrulaması yapılmıştır. Yapılan doğrulama sonuçlarına göre, sonlu eleman tipi, malzeme özelliği, sonlu eleman ağ aralığı ve doğrusal olmayan analizlerde ele alınan zaman adımı gibi parametreler sayısal analizlerde kullanılııștır. Bir dizi parametrik çalışma, ana elemanların geometrik özellikleri ve oriyantasyon tipleri dikkate alınarak gerçekleştirilmiştir. Sayısal analiz sonuçları eşdeğer kutu yöntemi ile karşılaştırılmıştır. Sayısal analiz sonuçlarına göre, mevcut yöntem ekonomik olmayan öngörülerde bulunduğu tespit edilmiştir. Ayrıca, tip 1 ve 2 ve tip 3 ve 4 oryantasyonları benzer davranışlara ve dayanımlara sahip olduğu gözlemlenmiştir. Bu yüzden, ekonomik ve güvenli bir yöntem geliştirilmiş ve sayısal modeller ile karşılaştırılmaları yapılarak doğrulanmıştır.
\end{abstract}

Anahtar kelimeler: Düzlem İçi Eğilme Momenti, Elips Enkesitli içi Boş Kesit (EHS), Oryantasyon Tipi, Sonlu Eleman Metodu, T- birleşimler

\begin{abstract}
Elliptical Hollow Sections (EHS) have become popular in recent years due to their aesthetic and elegant appearance. Apart from its architectural advantages, it has many advantages in terms of engineering. However, there is no design guide for the design of the joints made of EHS. In the structural applications, equivalent box profile approach is generally used. Since the EHSs have two different diameters, the joint can be formed by four different orientations. Therefore, the equivalent box profile approach may not always yield economic and safe results. The aim of this study is to examine the EHS T-joints in terms of their in-plane bending moment and their failure modes by using the equivalent box profile approach in the current design guides. This study was carried out using the non-linear finite element software ABAQUS v.6-14.1. Before numerical analysis, the finite element model was compared with an existing test. According to the validation results, parameters such as finite element type, material property, mesh size and time step taken in non-linear analyzes were used in parametric studies. A series of parametric analyses were carried out by taking into account the geometrical parameters and orientation types of the main elements. The results of the numerical analysis were compared with the equivalent box method. According to the results of the numerical analysis, it was found that the current method made non-economic predictions. In addition, the type 1 and 2 and type 3 and 4 orientations have similar behavior and strength. Therefore, an economical and safe method has been developed and verified by comparison with numerical models.
\end{abstract}

Keywords: Elliptical Hollow Section (EHS), Finite Element Method, In-plane bending moment, Orientation Type, Tjoints

\footnotetext{
*a Emre ÖZYURT; emre.ozyurt@gumushane.edu.tr; Tel: (0456) 23310 00; orcid.org/0000-0002-1465-596X

${ }^{\mathrm{b}}$ orcid.org/0000-0002-1873-6206
} 


\section{Giriş}

Elips en kesitli içi boş çelik profiller (EHS), yapısal tasarımlarımlarda kullanılan en son çelik profilidir. EHS, estetik görünümü ve bazı yapısal avantajları için dünya genelinde çeşitli yapılara uygulanmıştır. Ancak, bu uygulamalara yönelik herhangi bir tasarım yönetmeliği veya yöntemi mevcut değildir. Günümüzde, Çelik Yapıların Tasarım ve Yapım Kuralları (CYTYE, 2016) yönetmeliği, EHS'lerin tasarımına rehberlik etmemektedir. Ancak, bazı ulusulararası yönetmelikler, örneğin; Eurocode 1993-1-8 (CEN, 2005) ve CIDECT No.3 (Packer vd., 2009), EHS'ler üzerine ekonomik olmayan yöntemler içermektedir. Ayrıca, EHS'lerin köşelerinin olmaması nedeniyle korozyona karşı daha güçlü bir koruma sağladığı bilinmektedir (Ozyurt, 2018a). Bunların yanında, EHS'ler büyük ve küçük çaplara sahip olmalarından dolayı, rüzgara karşı avantaj sağlayacak şekilde tasarımı yapılabilmesi önemli avantajlarından birisidir. $\mathrm{Bu}$ gibi önemli özelliklerinden dolayı, bu profiller; havaalanları, köprüler, sergi salonları, stadyumlar, alışveriş merkezleri vb. birçok yapının tasarımında kullanılmaktadır (Bortolotti vd., 2003) (Şekil 1).

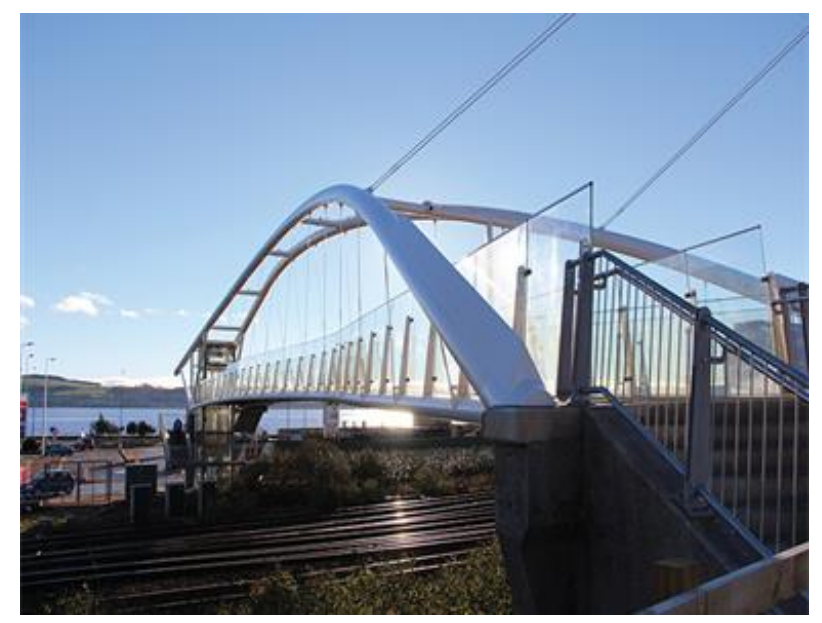

Şekil 1. EHS uygulamalarına bir örnek (URL-1)

Bortolotti vd. (2003) ve Pietrapetrosa vd. (2003), EHS $X$ ve N-birleşimlerinin eksenel yükleme altındaki dayanımlarını incelemişlerdir. EHS Tbirleşimlerinin iki farklı çapa sahip olmasının avantajından kaynaklanan dört farklı oryantasyon tipleri, Şekil 2'de gösterilmektedir.

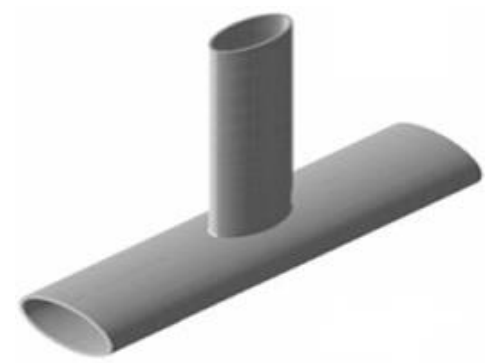

a) Tip 1

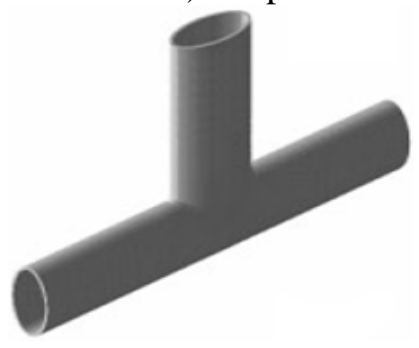

c) Tip 3

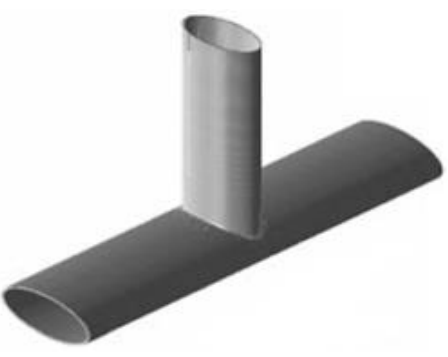

b) Tip 2

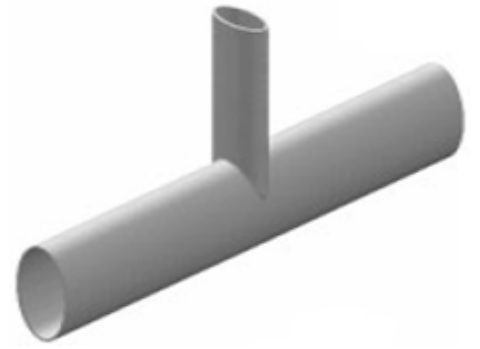

d) $\operatorname{Tip} 4$

Şekil 2. EHS T- birleşiminin farklı oryantasyon tipleri (Packer vd., 2012)

Choo vd. (2003a), bu dört farklı oryantasyon tiplerinin sonlu elemanlar yöntemleriyle davranışlarını araştırmıştır. Yaptıkları çalışmanın sonucunda, EHS X-birleşimlerinin yük taşıma kapasitelerinin, tip 4, 3, 2'den 1'e doğru azaldığ gözlemlemiş-lerdir. Wardenier (2007), EHS birleşimlerinin farklı göçme mekanizmalarını incelemiştir ve CIDECT yönetmeliğinde yer alan boru ve kutu enkesitli elemanların hesabı için önerilen denklemleri kullanarak EHS birleşimlerinin dayanımları için bir yöntem geliştirmiştir. Shen vd. (2012, 2013), dört farklı oryantasyon tipinden oluşan EHS Xbirleşimlerinin başlık elemanları basınç ve çekme 
kuvvetleri etkisindeyken davranışlarını incelemişlerdir. Yaptıkları çalışmalarının sonucunda, tip 1 ve 2 (bkz. Şekil 2. (a) ve (b)) oryantasyonları için EHS X-birleşimlerinin, kutu profillerden oluşmuş birleşimler ile davranış bakımından benzerlikler gösterdikleri sonucuna varmışlardır. Diğer tiplerdeki oryantasyonlarının (bkz. Şekil 2 (c) ve (d)) ise boru enkesitli elemanlardan oluşmuş birleşimlere benzer sonuçlar verdiğini saptamışlardır. Haque vd. (2012), 12 adet test gerçekleştirerek EHS X- ve Tbirleşimlerinin eksenel yük taşıma kapasitelerini incelemiş̧lerdir. Oryantasyon tipi, bağlantı açısı ve başlık elemanlarına uygulanan yük türünün etkileri araştırılmıştır. Buna ilaveten, birleşimlerin kapasitesini belirlerken eşdeğer kutu yaklaşımının, eşdeğer boru yaklaşımına göre daha iyi sonuçlar verebileceği kanısına varmışlardır. Packer vd. (2012), hem deneysel hem de sayısal analizler yaparak, EHS T- ve X-birleşimlerinin davranışlarını araştırmışlardır. Yapılan çalışmalarda, eşdeğer kutu veya boru birleşimlerinin güvenilir sonuçlar vermediğini saptamışlardır. EHS T- ve X-birleşimlerinin dayanımlarını hesaplamak için yaptıkları çalışma sonucunda yeni bir yöntem önermişlerdir. Ancak, önerilen bu yöntem, EHS T-birleşimlerinin eğilme momenti altındaki davranışını kapsamamaktadır. Literatür araştırmasından görüldüğü üzere, EHS T-birleşimlerinin eğilme momenti altındaki davranışları incelenmediği görünmektedir. $\mathrm{Bu}$ yüzden bu çalışmada, düzlem içi eğilme momenti etkisindeki EHS T-birleşimlerinin dayanımları ve göçme modları incelenmiştir.

\section{Sayısal Analizlerin Doğrulaması}

Literatür araştırmasından görüldügü üzere, düzlem içi eğilme momenti etkisinde EHS Tbirleşimleri ile ilgili herhangi bir çalışmaya rastlanmamıştır. Ancak, doğrulama çalışması için eğilme momenti altındaki boru profillerden üretilmiş (CHS) T-birleşimleri üzerine, Fung vd. (2016)'ne ait farklı sicaklıklarda testler mevcuttur. $\mathrm{Bu}$ çalışmada, yüksek sıcaklıklar dikkate alınmadığından Fung vd. (2016)'nin normal sıcaklıklarda yapmış oldukları test sonuçları kullanilarak sonlu elemanlar modelinin doğrulaması yapılmıştır.

Fung vd. (2016) yaptıkları çalışmada, tüm test numuneleri için S355 çelik sınıfını kullanmışlardır. Yaptıkları çelik çekme deneyinde S355 çeliğinin; karakteristik akma gerilmesini $\left(f_{y}\right)$ $380.3 \mathrm{~N} / \mathrm{mm}^{2}$, karaktersitik çekme dayanımını $\left(f_{u}\right)$ $519.1 \mathrm{~N} / \mathrm{mm}^{2}$ ve elastisite modülünü $(E) 201200$ MPa olarak bulmuşlardır.
ABAQUS'te girdi olarak kullanılacak malzeme özellikleri için aşağıda verilen eşitlik 1 ve 2 'den elde edilen dönüştürme işlemi sonucunda gerçek gerilme-birim şekil değiştirme eğrisi elde edilmiştir (Boresi ve Schmidt, 2003). Çünkü, ABAQUS kullanılarak doğrusal olmayan analizlerin yapılması ve yüksek deformasyonların elde edilebilmesi için bu dönüştürme işleminin yapılması gerekmektedir.

$$
\begin{aligned}
& \varepsilon_{T}=\ln (1+\varepsilon) \\
& \sigma_{T}=\sigma \times(1+\varepsilon)
\end{aligned}
$$

Bu eşitliklerde;

$\varepsilon:$ mühendislik birim şekil değiştirmesini

$\varepsilon_{T}$ : gerçek birim şekil değiştirmesini

$\sigma:$ mühendislik gerilmesini

$\sigma_{\mathrm{T}}$ :gerçek gerilmeyi göstermektedir.

Fung vd. (2016)'nin test kalibrasyon parametrelerini örnek alarak, doğrulaması yapılan CHS T-birleşiminin başlık elemanı iki ucu ankastre mesnetlenmiş, örgü elemanının ucunda ise düzlemde çalışabilmek için gerekli yerdeğiştirme ve dönmeler kısıtlanmıştır (Şekil 3). Başlık ve örgü elemanlarının çapları sırasıyla, $D=244.5 \mathrm{~mm}$ ve $d=168.3 \mathrm{~mm}$ 'dir. Yapisal elemanların et kalınlıkları (örgü elemanı için $(t)$ ve başlık elemanı için $(T)$ sembolleriyle) ise 6.3 mm'dir.

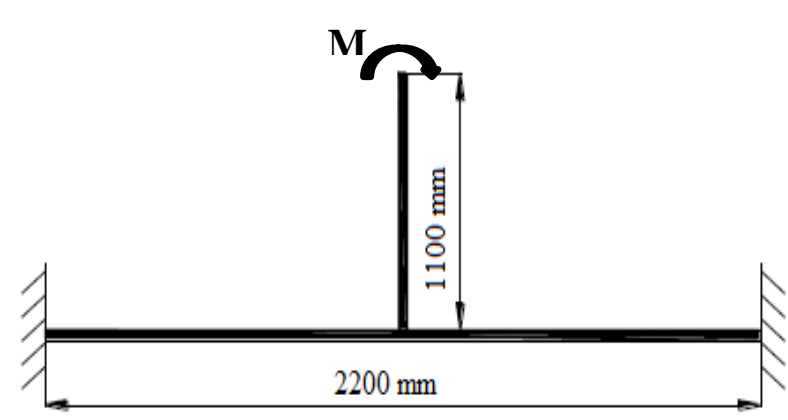

Şekil 3. Doğrulaması yapılan birleşimin mesnet koşulları

ABAQUS/Standart v.6-14.1 sonlu elemanlar programı kullanılarak oluşturulan doğrulama modeli Şekil 4'te gösterilmektedir. Doğrulama modelinden görüldüğg̈ üzere, yüklemelerin ve mesnet koşullarının tanımlanabilmesi için başlık ve örgü elemanlarına rijit levhalar eklenmiştir.

Şekil 5'te doğrulama modelinin sonlu eleman ağ aralıklarını ve kaynak detayını göstermektedir. Birleşim bölgesinde sık ağ aralıklarına $(6.3 \mathrm{~mm})$ bölünmüş olan modelde, birleşim bölgesinden uzak kısımlarda ise geniş ağ aralıklarına (12.6 
mm) bölünmüştür. Çünkü, gerilme dağılımının yüksek olacağı yerlerde ağ aralıklarının

sıklaştırılması güvenilir sonuçlara ulaşmakta yardımcı olmaktadır.

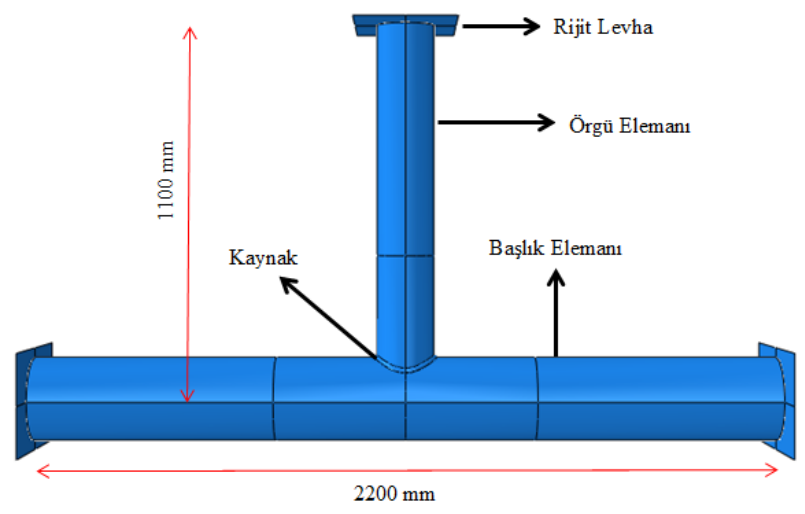

Şekil 4. CHS T-birleşiminin ABAQUS modelli

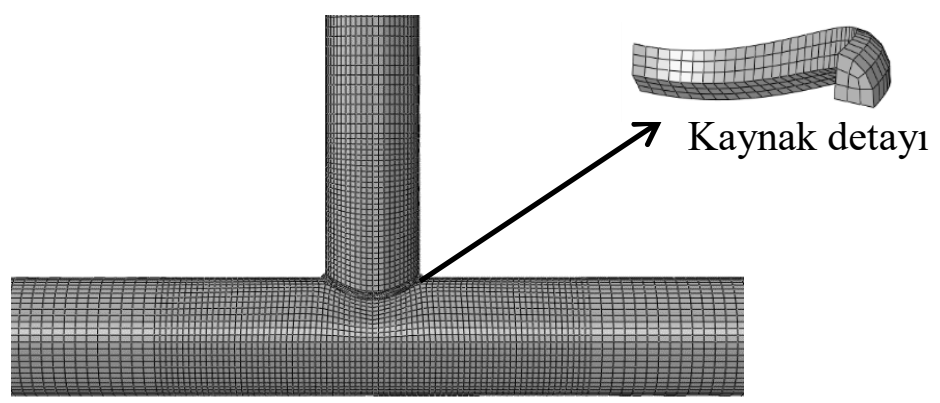

Şekil 5. CHS T- birleşiminin ağ aralıkları ve kaynak detayı

Şekil 6'da, test sonuçlarından ve sayısal analizlerden elde edilen moment-dönme miktarı eğrileri gösterilmektedir. Ayrıca, Yura'nın boru ve kutu profiller için önerdiği ve günümüzde hala kabul edilen maksimum dönme sinırlamasını göstermektedir (Yura vd., 1980). Yura'nın eğilme momenti etkisindeki boru ve kutu birleşimler için dönme sinırlaması, $80 f_{y} / E$ ( $f_{y}$ akma gerilmesi ve $E$, elastisite modülü) olarak belirtilmiştir. $\mathrm{Bu}$ sınırlamaya göre, moment-dönme eğrisinde, maksimum eğilme momenti dönme sınırlamasından önce meydana gelirse, birleşimin eğilme dayanımı maksimum değere eşittir. Ancak, maksimum moment dönme sınırlamasından sonra oluşursa, birleşimin eğilme momenti dayanımı dönme sınırlamasına karşılık gelen moment değerine eşittir. Sonlu elemanlar modelinin sonuçları ve Fung vd. (2016)'nin test sonuçları karşılaştırıldığında, Şekil 6'da gösterildiği gibi çok yakın değerler elde edilmiştir. Bu doğrulama çalışmasının sonucundan anlaşılacağı üzere, bu çalışmada oluşturulacak eğilme momenti etkisindeki EHS T-birleşimlerine ait sayısal modellerin, doğru ve güvenilir sonuçlar vermesi öngörülmektedir.
Şekil 6. Fung vd., (2016)'nin test sonuçları ile sayısal analiz sonuçlarının karşılaştırılması

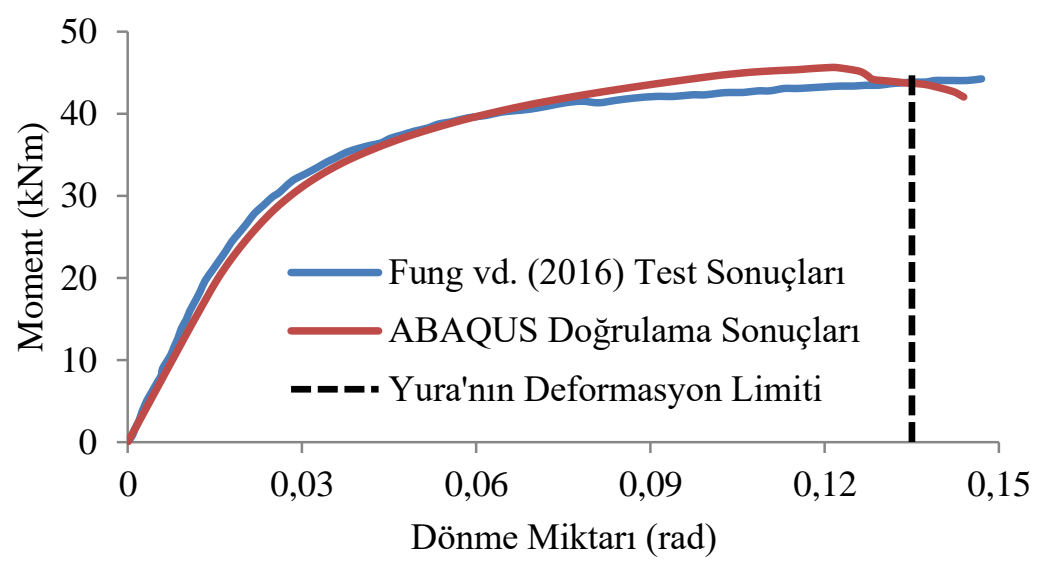




\section{Sayısal Analizler}

Yapılan doğrulama çalışmasından elde edilen sonuçlar 1şı̆̆ında doğrulanmış modelde kullanılan; sonlu eleman tipi, malzeme özelliği, sonlu eleman ağ aralığ zaman adımı gibi parametreler, EHS çelik Tbirleşimlerinin modellenmesi için sayısal analizlerde de kullanılmıştır.

EHS'ler iki farklı çap boyutlarına sahip olduklarından ötürü, T-birleşimlerinin dört farkl1 oryantasyon tipi mevcuttur. Bu çalışmada, farklı geometrik kombinasyonlarından ve oryantasyonlarından elde edilen toplam 19 birleşimin doğrusal olmayan sayısal analizlerle, ABAQUS v.6-14.1 (2014) programında modellenerek incelenmiştir. $\mathrm{Bu}$ bahsedilen birleşim parametreleri, Tablo 1' de sunulmuştur. Mesnet koşullarının etkilerini minimuma indirgemek için başlık ve örgü elemanlarının uzunlukları sırasıyla, başlık eleman çapının en az on katı, örgü eleman çapının en az 6 katı kadar olmas1 gerekmektedir (Ozyurt vd., 2018b). Tablo 1 'de bu durum dikkate alınarak belirlenmiştir.

Tablo 1. Sayısal analizlerde ve analitik hesaplamalarda kullanılan birleşimlerin geometrik özellikleri

\begin{tabular}{|l|l|l|l|l|l|l|l|l|}
\hline \multirow{2}{*}{$\begin{array}{l}\text { Birleşim } \\
\text { Numaras1 }\end{array}$} & \multicolumn{3}{|l}{ Başlık Elemanı Boyutlar1 } & \multicolumn{3}{l}{ Ögü Elemanı Boyutlar1 } \\
\cline { 2 - 9 } & $\mathrm{B}(\mathrm{mm})$ & $\mathrm{D}(\mathrm{mm})$ & $\mathrm{T}(\mathrm{mm})$ & $\mathrm{L}(\mathrm{mm})$ & $\mathrm{b}(\mathrm{mm})$ & $\mathrm{d}(\mathrm{mm})$ & $\mathrm{t}(\mathrm{mm})$ & $1(\mathrm{~mm})$ \\
\hline T1-1 & 300 & 150 & 8 & 3000 & 125 & 250 & 8 & 1500 \\
\hline T2-1 & 300 & 150 & 8 & 3000 & 250 & 125 & 8 & 1500 \\
\hline T3-1 & 150 & 300 & 8 & 3000 & 125 & 250 & 8 & 1500 \\
\hline T1-2 & 300 & 150 & 8 & 3000 & 100 & 200 & 8 & 1200 \\
\hline T2-2 & 300 & 150 & 8 & 3000 & 200 & 100 & 8 & 1200 \\
\hline T3-2 & 150 & 300 & 8 & 3000 & 100 & 200 & 8 & 1200 \\
\hline T1-3 & 300 & 150 & 8 & 3000 & 75 & 150 & 8 & 900 \\
\hline T2-3 & 300 & 150 & 8 & 3000 & 150 & 75 & 8 & 900 \\
\hline T3-3 & 150 & 300 & 8 & 3000 & 75 & 150 & 8 & 900 \\
\hline T1-4 & 300 & 150 & 8 & 3000 & 125 & 250 & 6.3 & 1500 \\
\hline T2-4 & 300 & 150 & 8 & 3000 & 250 & 125 & 6.3 & 1500 \\
\hline T3-4 & 150 & 300 & 8 & 3000 & 125 & 250 & 6.3 & 1500 \\
\hline T1-5 & 300 & 150 & 8 & 3000 & 125 & 250 & 12.5 & 1500 \\
\hline T2-5 & 300 & 150 & 8 & 3000 & 250 & 125 & 12.5 & 1500 \\
\hline T3-5 & 150 & 300 & 8 & 3000 & 125 & 250 & 12.5 & 1500 \\
\hline T1-6 & 400 & 200 & 8 & 4000 & 75 & 150 & 8 & 900 \\
\hline T2-6 & 400 & 200 & 8 & 4000 & 150 & 75 & 8 & 900 \\
\hline T3-6 & 200 & 400 & 8 & 4000 & 75 & 150 & 8 & 900 \\
\hline T4-6 & 200 & 400 & 8 & 4000 & 150 & 75 & 8 & 900 \\
\hline
\end{tabular}

Tabloda verilen birleşim numaraları; örnek olarak, T1-1 numaralandırılmasında, $\mathrm{T}$ harfi birleşim tipini(T-birleşim), ilk rakam oryantasyon tipini, son rakam ise birleşim numarasinı temsil etmektedir. Bu numaralandırmaya göre, toplam 6 tür birleşim söz konusudur. $B$ ve $b$ harfleri sırasıyla, başlık ve örgü elemanlarının düzleme dik çaplarını, $D$ ve $d$ ise sırasıyla, başlık ve örgü elemanlarının düzlemdeki çap boyutlarını, $T$ ve $t$ sırasıyla, başlık ve örgü elemanlarının et kalınlıklarını, son olarak $L$ ve $l$ sırasıyla başlık ve örgü elemanlarının uzunluklarını göstermektedir.

Yapılan tüm sayısal analizlerde S355 çelik sınıfı kullanılmıştır. S355 çeliğinin karakteristik akma gerilmesi $\left(f_{y}\right) \quad 355 \mathrm{~N} / \mathrm{mm}^{2}$ ve karaktersitik çekme mukavemeti $\left(f_{u}\right) 510 \mathrm{~N} / \mathrm{mm}^{2}$ 'dir. Çeliğin elastisite modülü $(E) 210 \mathrm{GPa}$ ve poisson oranı $(v)$
0.3 olarak varsayılmıştır. Malzeme özelliklerinin ABAQUS girdisinde, doğrulma çalışmasında yapıldığ 1 gibi parametrik çalışmalarda da gerçek gerilme-birim şekil değiştirme eğrisi kullanılmıştır.

Tablo 1'de geometrik boyutları verilen, EHS Tbirleşimlerinin sonlu elemanlar yöntemi kullanılarak modellenmiş ve düzlem içi eğilme moment etkisi altında dayanımları ve göçme modları Yura'nın maksimum dönme sınırı $\left(=80 f_{y} / E\right)$ dikkate alınarak incelenmiştir.

\subsection{Göçme Modu ve Ĕgilme Momenti Dayanimları}

Bu bölüm, Tablo 1'de belirtilen birleşimlerin sayısal analiz sonuçlarını kapsamaktadır. 
Göçme modları ve dayanımları karşılaştırılarak, EHS T-birleşimleri hakkında önemli bilgilere ulaşılmıştır. Sayısal analiz sonuçlara göre, tüm birleşim türü ve oryantasyonları için, başlık elemanında plastikleşme gözlemlenmiştir. Şekil 7'de, farklı oryantasyon tipine sahip aynı birleşim türüne ait şekil değiştirmiş T-birleşimleri gösterilmektedir. Şekil 7'den görüleceği üzere, örgü elemanına uygulanan eğilme momenti sonucunda, tüm oryantasyon tiplerinin birleşim bölgesinde kalan başlık elemanı yerel olarak deformasyonlara uğramıştır. Yönetmeliklerde de bu durum dikkate alınmıştır ve boru ve kutu enkesiler için en kritik göçme modu, başlik elemanında plastikleşme olarak belirtilmiştir. Ancak bu durumun gerçekleşebilmesi için örgü elemanının çapı başıık elemanının çapına oranı, $\beta$, 0.85 'ten küçük olması ve kaynak elemanında her hangi bir göçme olmaması koşullarının sağlanmasında geçerlidir.

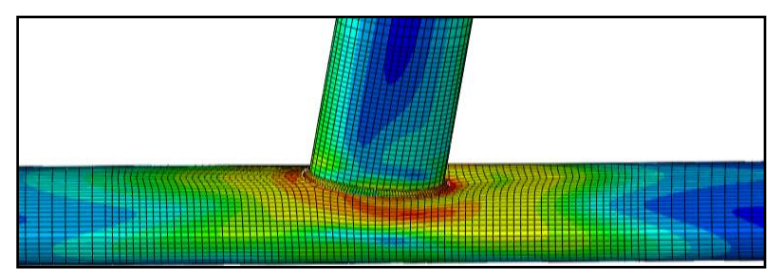

a) $\mathrm{T} 1-2$

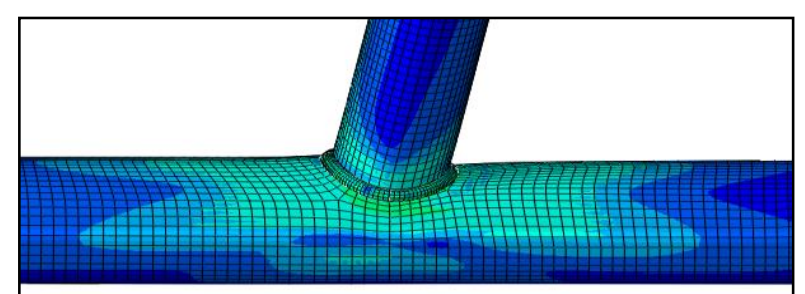

b) $\mathrm{T} 2-2$

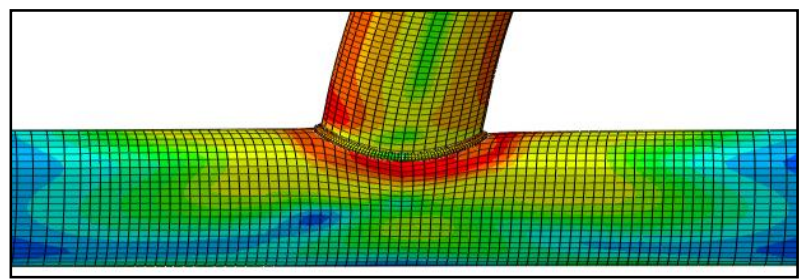

c) $\mathrm{T} 3-2$

Şekil 7. Parametrik çalışmaya ait üç farklı oryantasyon türlerinin deformasyonları

Şekil 8'de, örnek olarak T1-2, T2-2 ve T3-2 birleşimlerinin moment-dönme miktarı eğrileri karşılaştırılmıştır. Şekil 8' den görüleceği gibi, maksimum dayanım T3-2 (Tip-3)'ye aittir. Çünkü, tip 3 ve 4 oryantasyonlarında başlik elemanı kuvvetli eksen üzerinde çalışmaktadır (başlik elemanının büyük çapı düzlemde görülmektedir). En düşük dayanıma sahip olan birleşim ise, T2-2 (Tip-2)' dir. Tip 1 ve 2 oryantasyonlarında, başlık elemanı ataleti zayıf olan eksene göre yerleştirilmiştir. Şekil 8'de gösterilen eğrilerden anlaşılacağı üzere, en fazla dayanıma sahip olan T3-2, diğer oryantasyon tipleri ile karşılaştırıldığında aynı zamanda en rijit birleşim türüdür. Ancak, estetik açıdan düşünüldüğünde, en avantajlı olan tip 2 oryantasyonu olduğu unutulmamalıdır.

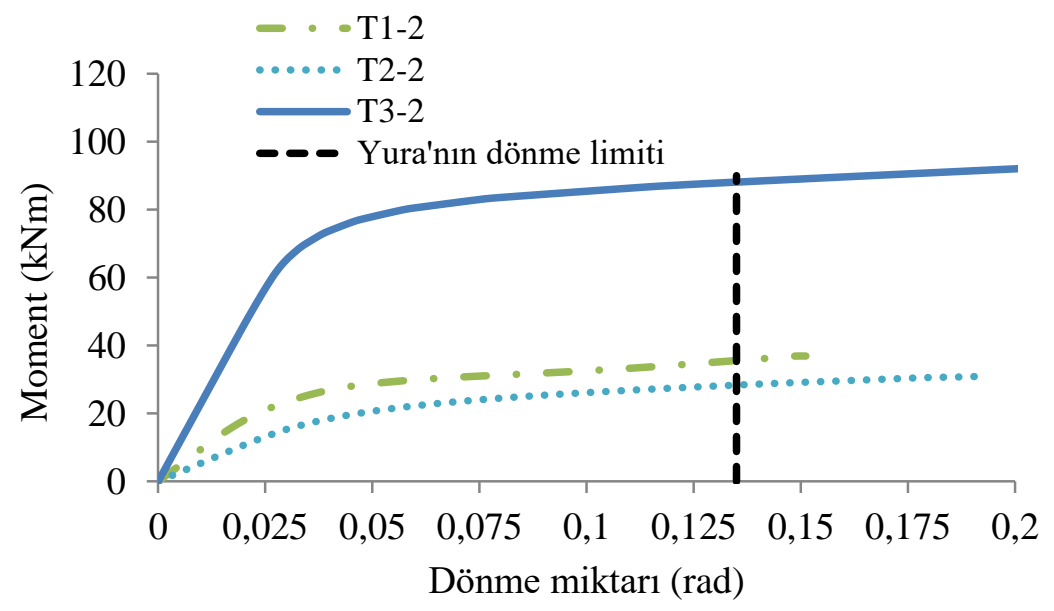

Şekil 8. T1-2, T2-2, T3-2 birleşimlerinin moment- dönme grafiğgi 
Yapılan tüm sayısal analiz sonuçlarından elde edilen, EHS T-birleşimlerinin düzlem içi eğilme momenti dayanımları, Tablo 2'de sunulmuştur. Tüm birleşim dayanımları incelendiğinde, tip 1 ve 2 oryantasyonları ile tip 3 ve 4 oryantastonları benzer sonuçlar verdiği gözlemlenmiştir. Ayrıca, tip 3 ve 4 oryantasyonlarının, tip 1 ve 2 oryantasyon tiplerine göre yaklaşı olarak üç kat daha fazla dayanıma sahip olduğu söylenebilir.

Tablo 2. ÇYTYE (2016) öngörüleri ile sayısal analiz sonuçlarının karşılaştırılması

\begin{tabular}{|l|l|l|l|}
\hline $\begin{array}{l}\text { Birleşim } \\
\text { Numaras1 }\end{array}$ & ABAQUS sonuçları $(\mathrm{kNm})$ & $\begin{array}{l}\text { ÇYTYE (2016) } \\
(\mathrm{kNm})\end{array}$ & $\begin{array}{l}\text { ABAQUS sonuçlarının } \\
\text { ÇTYE (2016)'ye oranı }\end{array}$ \\
\hline T1-1 & 40.5 & 18.9 & 2.14 \\
\hline T2-1 & 47.1 & 17.5 & 2.70 \\
\hline T3-1 & 140.9 & 72.4 & 1.95 \\
\hline T1-2 & 35.6 & 13.5 & 2.64 \\
\hline T2-2 & 28.3 & 9.6 & 2.94 \\
\hline T3-2 & 88.1 & 27.7 & 3.17 \\
\hline T1-3 & 22.2 & 9.6 & 2.31 \\
\hline T2-3 & 17.2 & 6.7 & 2.58 \\
\hline T3-3 & 46.8 & 13.3 & 3.51 \\
\hline T1-4 & 49.8 & 18.9 & 2.63 \\
\hline T2-4 & 47.6 & 17.5 & 2.73 \\
\hline T3-4 & 112.4 & 72.4 & 1.55 \\
\hline T1-5 & 53.7 & 18.9 & 2.83 \\
\hline T2-5 & 55.2 & 17.5 & 3.16 \\
\hline T3-5 & 168.9 & 72.4 & 2.33 \\
\hline T1-6 & 19.0 & 9.9 & 1.92 \\
\hline T2-6 & 13.1 & 7.2 & 1.82 \\
\hline T3-6 & 34.1 & 10.7 & 3.20 \\
\hline T4-6 & 29.8 & 8.2 & 3.62 \\
\hline
\end{tabular}

\section{2. Çelik Yapıların Tasarım Ve Yapım Esasları (ÇYTYE, 2016)' na Göre Tasarım}

$\mathrm{Bu}$ kısımda, mevcut yönetmelikte yer alan boru ve kutu profiller için önerilen tasarım yöntemi, EHS T-birleşimleri için uygulanmıştır. Literatür çalışmalarından görüleceği üzere, kutu profiller, EHS'ye daha yakın sonuçlar vermektedir. Bu yüzden, bu çalışmada da kutu profiller için önerilen tasarım yöntemi dikkate alınmıştır. Ayrıca, yönetmeliklerdeki denklemlerin kullanılabilmesi için, Haque vd. (2012)'nin önerdiği EHS'lerin eşdeğer kutuya dönüştürülmesi de dikkate alınmıştır. Bu şekilde, bütün birleşim ve oryantasyonları için, Çelik Yapıların Tasarım ve Yapım Esasları (ÇYTYE, 2016) yönetmeliğindeki eşitlik 3 kullanılarak eşdeğer kutu yöntemine göre EHS Tbirleşimlerinin dayanımları karşılaştımalı olarak Tablo 2' de sayısal analizlerden elde edilmiş dayanımlar ile birlikte sunulmuştur. Eşitlik 3 'te kullanilan semboller $\eta$ ve $Q_{f}$, sirasiyla kutu enkesitler için uygulanan yük etkime uzunluğu ve başlık elemanı gerilme etkileşimidir. Karşılaştırmalardan görüleceği üzere, ÇYTYE (2016)'ye göre dayanım tahminleri gerçek dayanımlara göre hiç ekonomik olmayan sonuçlar vermektedir. $\mathrm{Bu}$ durum, EHS T-birleşimlerinin dayanımlarını ekonomik olmayacak şekilde tasarlanmasına neden olabilmektedir.

$M_{n}=F_{y} t^{2} d\left[\frac{1}{2 \eta}+\frac{1}{\sqrt{1-\beta}}+\frac{\eta}{(1-\beta)}\right] Q_{f}$

$\mathrm{Bu}$ çalışmasının asıl amacı, bu dayanım tahminlerinin incelenmesidir. Eğer, güvenli veya ekonomik olmayan yaklaşımlar söz konusu olması durumunda ise, yeni ve güvenli bir yöntem önerilerek, EHS T birleşimlerinin düzlem içi eğilme dayanımlarının hesaplanılabilmesini sağlamaktır.

\section{4. Önerilen Tasarım Methodu}

Çelik Yapıların Tasarım ve Yapım Esasları (ÇYTYE, 2016)'nda, kutu enkesili Tbirleşimlerinin dayanımlarını hesaplamak için denklemler sunulmuştur. Ancak, bahsedilen yönetmelikteki eşdeğer kutu yöntemi ile EHS Tbirleşimlerinin dayanımları, sayısal analizlerden elde edilen sonuçlar ile karşılaştırıldığında ekonomik olmayan tahminler elde edildiği 
saptanmıştır. $\quad \mathrm{Bu}$ yüzden, parametrik çalışmalardan elde edilen sonuçlar doğrultusunda, EHS T-birleşimlerinin dayanımlarını güvenli ve ekonomik olarak hesaplanabilmesi için yeni bir yönteme ihtiyaç duyulmaktadır.

Bir önceki bölümde bahsedildiği gibi, EHS Tbirleşimleri için tip 1 ve 2 oryantasyonlarının davranışları ile tip 3 ve 4 oryantasyonlarının davranışları kendi aralarında benzerlik gösterdiği saptanmıştır. $\mathrm{Bu}$ yüzden, önerilen tasarım yönteminde bu ikili oryantasyonlar için ayrı ayrı tasarım yöntemi, çok değişkenli doğrusal regresyon analizi kullanılarak geliştirilmiştir. Microsoft Excel'den elde edilen regresyon analizinde; $\eta, \beta, D$ ve $t$ parametreleri bağımsız, sayısal analiz sonuçlarının analitik sonuçlara oranları ise bağımlı parametreler olarak dikkate alınacaktır.

\subsection{Tip 1 ve 2 Oryantasyonları İçin Önerilen Yöntem}

Başlık elamanının zayıf eksende çalıştı̆̆ oryantasyon tipleri, 1 ve 2 numaral1 oryantasyonlardır. Tablo 3'de EHS Tbirleşimlerinin tip 1 ve tip 2 oryantasyonlarına ait sayısal analiz sonuçlarının ÇYTYE (2016) sonuçlarına oranlarının ve regresyon analizinde kullanılan değişken parametrelerinin $(\eta, \beta, D$ ve $t)$ özetini sunmaktadır.

Tablo 3. Sayısal analiz sonuçlarının yönetmelik sonuçlarına oranları ve regresyon analizinde kullanılan değişken parametreler (Tip 1 ve Tip 2 için)

\begin{tabular}{|l|l|l|l|l|l|}
\hline & ABAQUS/ÇYTYE & $\eta=\frac{d}{B}$ & $\beta=\frac{b}{B}$ & $D$ & $t$ \\
\hline T1-1 & 2.14 & 0.83 & 0.42 & 150 & 8 \\
\hline T2-1 & 2.70 & 0.42 & 0.83 & 150 & 8 \\
\hline T1-2 & 2.64 & 0.67 & 0.33 & 150 & 8 \\
\hline T2-2 & 2.94 & 0.33 & 0.67 & 150 & 8 \\
\hline T1-3 & 2.31 & 0.50 & 0.25 & 150 & 8 \\
\hline T2-3 & 2.58 & 0.25 & 0.50 & 150 & 8 \\
\hline T1-4 & 2.63 & 0.83 & 0.42 & 150 & 6.3 \\
\hline T2-4 & 2.73 & 0.42 & 0.83 & 150 & 6.3 \\
\hline T1-5 & 2.83 & 0.83 & 0.42 & 150 & 12.5 \\
\hline T2-5 & 3.16 & 0.42 & 0.83 & 150 & 12.5 \\
\hline T1-6 & 1.92 & 0.38 & 0.19 & 200 & 8 \\
\hline T2-6 & 1.82 & 0.19 & 0.38 & 200 & 8 \\
\hline
\end{tabular}

Yapılan parametrik analizlerden elde edilen sonuçlar 1şı̆̆ında, çok değişkenli doğrusal regresyon analizi yapılarak, ÇYTYE (2016) için önerilen düzeltme katsayısı çarpanı ( $\psi$ ) eşitlik 4'te verilmektedir.

$\psi=3.68-0.12 * \eta+0.65 * \beta-0.012 * D+$ $0.063 * t$

\subsection{Tip 3 ve 4 Oryantasyonları İçin Önerilen Yöntem}

Başlık elamanının güçlü eksende çalıştığı oryantasyon tipleri, 3 ve 4 numaralı oryantasyonlardir. Tablo 3'de EHS Tbirleşimlerinin, tip 3 ve tip 4 oryantasyonlarına ait sayısal analiz sonuçlarının ÇYTYE (2016) sonuçlarına oranlarının ve regresyon analizinde kullanılan değişken parametrelerinin $(\eta, \beta, D$ ve $t)$ özetini sunmaktadır.
Yapılan parametrik analizlerden elde edilen sonuçlar 1şığında, çok değişkenli doğrusal regresyon analizi yapılarak, ÇYTYE (2016) için önerilen düzeltme katsayısı $(\psi)$ çarpanı eşitlik 5'de verilmektedir.

$\psi=9.05-2.18 * \eta-1.06 * \beta-0.012 * D+$ $0.109 * t$

\section{3. Önerilen Tasarım Metodunun Uygulaması}

Eşdeğer kutu yöntemine göre, ÇYTYE (2016)'da önerilen mevcut yöntem, eşitlik 3'te verilmiştir. $\mathrm{Bu}$ parametrik çalışmada, ÇYTYE için kullanılması önerilen katsayı çarpanı $(\psi)$ ise eşitlik 4 ve 5'te, sırasıyla tip 1 ve 2 ve tip 3 ve 4 oryantasyonları için verilmiştir. Ancak, doğrudan regresyon analizlerinden elde edilen bu katsayıya, her zaman güvenli tarafta kalınabilmesi için güvenlik katsayısının eklenmesi gerekmektedir. 
Tablo 4. Sayısal analiz sonuçlarının yönetmelik sonuçlarına oranları ve regresyon analizinde kullanılan değişken parametreler (Tip 3 ve Tip 4 için)

\begin{tabular}{|l|l|l|l|l|l|}
\hline & ABAQUS/ÇYTYE & $\eta=\frac{d}{B}$ & $\beta=\frac{b}{B}$ & $D$ & $t$ \\
\hline T3-1 & 1.95 & 1.67 & 0.83 & 300 & 8 \\
\hline T3-2 & 3.17 & 1.33 & 0.67 & 300 & 8 \\
\hline T3-3 & 3.51 & 1.00 & 0.50 & 300 & 8 \\
\hline T3-4 & 1.55 & 1.67 & 0.83 & 300 & 6.3 \\
\hline T3-5 & 2.33 & 1.67 & 0.83 & 300 & 12.5 \\
\hline T3-6 & 3.20 & 0.75 & 0.38 & 400 & 8 \\
\hline T4-6 & 3.62 & 0.38 & 0.75 & 400 & 8 \\
\hline
\end{tabular}

Bu katsayı, önerilen yöntem sonuçlarının sayısal analiz sonuçlarına oralarından en küçük değer olarak alınması ile mümkün olabilmektedir. Bu yüzden, 0.90 olan güvenlik çarpanı, $\psi$ katsayısına eklenmesi önerilmektedir. Sonuç olarak, EHS Tbirleşimlerinin düzlem içi eğilme momenti etkisi altındaki davranışları yukarıda bahsedilen durumlar doğrultusunda, eşitlik 6'da genel olarak önerilen yöntem ifade edilmiştir.

$M_{n}=F_{y} t^{2} d\left[\frac{1}{2 \eta}+\frac{1}{\sqrt{1-\beta}}+\frac{\eta}{(1-\beta)}\right] Q_{f} \psi$

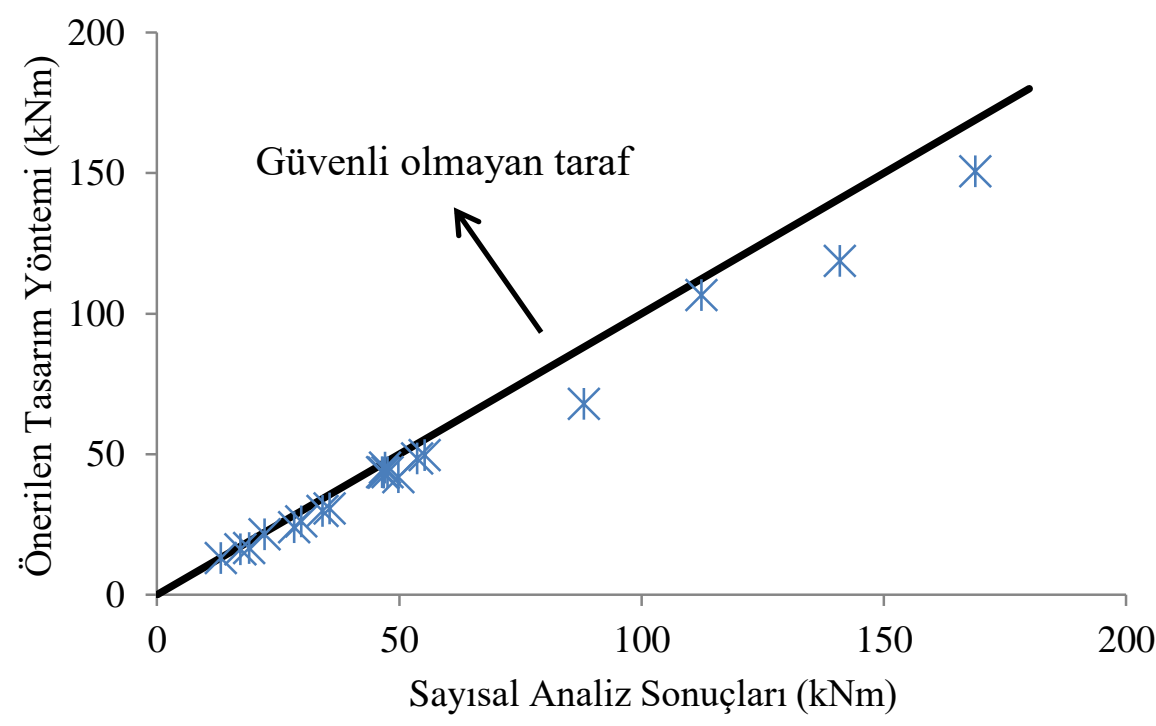

Şekil 9. Önerilen tasarım yönteminin parametrik analiz sonuçları ile karşılaştırılması

\section{Sonuçlar}

$\mathrm{Bu}$ çalışmada, kaynaklı EHS T-birleşimlerinin düzlem içi eğilme momenti altında davranışları ABAQUS/Standart v.6-14.1 (2014) sonlu elemanlar paket programı kullanılarak incelenmiştir. Doğrulama çalışması yapıldıktan sonra elde edilen parametrik çalışmalar
Tablo 1'de verilen tüm birleşim ve oryantasyonları için, önerilen tasarım yöntemi kullanılarak hesaplanmış olan EHS Tbirleşimlerinin dayanımlarıile yapılan tüm sayısal analiz sonuçlarının karşılaştırılması Şekil 9‘da gösterilmektedir. Önerilen tasarım yöntemi sonuçları, yapılan parametrik çalışma sonuçları ile yaklaşık sonuçlar vermiş olduğu tespit edilmiştir. Tablo 2'de yapılan mevcut yönetmelik öngörü sonuçları gerçek dayanım değerlerinin çok altında olduğu ve aynı zaman da önerilen tasarım methodunun gerçek dayanıma çok yakın değerler vermesinden ötürü EHS T birleşimlerinin düzlem içi eğilme dayanımlarının eşitlik 6 kullanılarak hesaplanması önerilmektedir. 
2-) En kritik göçme modu, oryantasyon tipinden bağımsız olarak başlık elemanında plastikleşmedir.

3-) CYTYE (2016)'de belirtilen kutu birleşimlerin dayanım hesaplamaları eşdeğer kutu yöntemi kullanılmasına rağmen, EHS birleşimlerinin dayanımlarının hesaplanması için yetersizdir.

4-) Çok değişkenli doğrusal regresyon analizine dayanan tasarım yöntemi ile güvenlik katsayısı çarpanı kullanılarak, EHS Tbirleşimlerinin eğilme momenti dayanımı güvenli ve ekonomik olarak hesaplanabilmektedir.

\section{Kaynaklar}

ABAQUS, V.,2014. 6.14 documentation, Dassault Systems Simula Corporation

Boresi, A. P. ve Schmidt, R. J., 2003. Advanced Mechanics of Materials, John Wiley and Sons Press, USA.

Bortolotti, E., Jaspart, J. P., Pietrapertosa, C., Nicaud, G., Petitjean, P. D. ve Grimault, J. P., 2003. Testing and Modelling of Welded Joints Between Elliptical Hollow Sections, Proceedings of the 10th International Sympsium on Tubular Structures, Madrid, Spain, p. 259264.

CEN EN 1993-1-8, 2005. Design of Steel Structures, Design of Joints, British Standart Institute, London.

Choo, Y. S., Liang, J. X. ve Lim, L. V., 2003a. Static Strength of Elliptical Hollow Section X- Joint Under Brace Compression, Tubular Structures $\mathrm{X}$, Proceedings of the 10th International Symposium, Madrid, Spain, p. 253-258.

CYTYE, Türk Standartları Enstitüsü, 2016. Çelik Yapıların Tasarım ve Yapım Kuralları, Ankara.

Fung, T. C., Tan, K. H. ve Nguyen, M. P., 2015. Structural Behaviours of CHS T- Joints Subjected to Static In- Plane Bending in Fire Conditions, Journal of Structural Engineering, $142,04015155$.

Haque, T., Packer, J. A. ve Zhao, X-L., 2012. Equivalent RHS Approach for The Design of
EHS in Axial Compression or Bending, Advances in Structural Engineering, 15, 107120.

Ozyurt, E. ve Wang, Y. C., 2018b. Resistance of Axially Loaded $\mathrm{T}$-and X-Joints of Elliptical Hollow Sections at Elevated Temperatures-A Finite Element Study. Structures, 15-31.

Ozyurt, E., 2018a. Yanginda Elips Enkesitli Eksenel Yük Taşıyan Çelik Kolonların Davranışı, Uludağ Üniversitesi Mühendislik Fakültesi Dergisi, Bursa, 23, 205-206.

Packer, J. A., Choo, Y. S., Shen, W., Wardenier, J., Van der Vegte, G. J. ve Mustard, T., 2012. Axially Loaded $\mathrm{T}$ and $\mathrm{X}$ Joints of Elliptical Hollow Sections, CIDECT Final Report No. $5 \mathrm{BW}-2$.

Packer, J. A., Wardenier, J., Zhao, X. L., Van der Vegte, G. J. ve Kurobane, Y., 2009. Design Guide for Rectangular Hollow Section (RHS) Joints Under Predominantly Static Loading, 2nd Edition, No.3, CIDECT.

Pietrapertosa, C. Ve Jaspart, J. P., 2003. Study of the Behaviour of Welded Joints Between Elliptical Hollow Sections, Proceedings of the 10th İnternational Symposium on Tubular Structures.

Shen, W., Choo, Y. S., Wardenier, J. ve Van der Vegte, G. J., 2012. Static Strength of Axially Loaded Elliptical Hollow Section X Joints with Braces Welded to Wide Sides of Chord, I: Numerical Investigations Based on Experimental Tests. Journal of Structural Engineering, 140, 04013035 .

Shen, W., Choo, Y. S., Wardenier, J. ve Van der Vegte, G. J., 2013. Static Strength of Axially Loaded EHS X-Joints with Braces Welded to the Narrow Sides of the Chord. Journal of Constructional Steel Research, 88, 181-190.

Wardenier, J., 2007. Elliptical Hollow Sections, Internal Report Prepared for Corus.

Yura, J. A., Zettlemoyer, N. ve Edwards, I. E., 1980. Ultimate Capacity of Circular Tubular Joints, Proceedings of Offshore Technology Conference, p. 1965-1984.

URL- $1, \quad$ https://www.bimobject.com/en-us/tatasteel/product/celsius-355-ehs, 14 Aralık 2018. 